PALAVRAS. Revista de Epistemología, Metodología y Ética del Psicoanálisis

ISSN: 2468-9831

www.revistas.unlp.edu.ar/palavras

palavras@outlook.com.ar

Argentina

\title{
LA CRÍTICA: UNA CONTRIBUCIÓN DE LA TEORÍA DE GÉNERO PARA ENTENDER LA FEMINIDAD.
}

DOI $10.24215 / 24689831 \mathrm{e} 008$

\section{Rolando Héctor Casale}

\begin{abstract}
We understand critique as an attitude that enhances the limits of knowledge. In particular, the critique of the gender theory about diverse areas of knowledge has revealed that many statements about women do not correspond with the scientific objectivity but they correspond with the male interest to maintain their domination over them.

An example of this kind of criticism is found in the book Speculum of the Other Woman, written by Luce Irigaray, who evaluates the way in which Freud describes female sexuality, revealing that many of the statements about women stated by Freud lack legitimacy and basis from the epistemological point of view, which shows its relationship with the exercise of patriarchal power. In the present article, we are going to deal with Butler's way of critique in her article What is critique?, where she says that it has political, ethical and epistemological aspects.

We consider that this type of criticism would be very beneficial for Psychoanalysis.
\end{abstract}

Key-words: Critique, Femininity, Gender, Psychoanalysis.
Resumen

Vamos a concebir la crítica como una actitud que pone de relieve los límites de un conjunto de conocimientos. En particular, la crítica de la teoría de género realizada sobre distintos ámbitos del saber ha mostrado que muchas de las afirmaciones sobre las mujeres no obedecen a la objetividad, sino que se corresponden con a intereses de los varones para mantener su dominación sobre éstas.

Un ejemplo de ejercicio de esa critica es la investigación realizada por Luce Irigaray en su libro titulado Espéculo de la otra mujer, donde analiza la forma en que Freud describe la sexualidad femenina, revelando que muchas de las proposiciones ahí sostenidas carecen de legitimidad y sustento desde el punto de vista epistemológico; pero que muestran su relación con el ejercicio del poder patriarcal.

Se profundizará luego el modo de proceder crítico llevado adelante desde la perspectiva de Género, en base a la concepción de crítica sostenida por Butler en ¿Qué es la critica?, donde se muestra que la misma tiene aspectos políticos, éticos $\mathrm{y}$ epistemológicos.

Consideramos que ésta forma de ejercer la critica podría ser muy beneficiosa para el psicoanálisis.

Palabras clave: Critica, Feminidad, Género, Psicoanálisis.

\section{Cómo citar este artículo:}

Casale, R. H. (2016). La crítica: una contribución de la Teoría de Género para entender la feminidad. Palavras. Revista de Epistemología, Metodología y Ética del Psicoanálisis, 2, 1842. Recuperado de www.revistas.unlp.edu.ar/palavras 


\section{LA CRÍTICA: UNA CONTRIBUCIÓN DE LA TEORÍA DE GÉNERO PARA ENTENDER LA FEMINIDAD}

\section{Rolando Casale*}

\section{Introducción}

Concebimos la crítica como una actividad expresada en una actitud por medio de la cual se pone en cuestión al saber; sostenemos junto a Butler y Foucault que dicha actividad tiene alcances epistémicos, éticos y políticos; y que una de las características distintivas de la misma es su historicidad. Nuestra tesis central sostenida en este trabajo es que la lectura que efectúa Irigaray de la conferencia freudiana sobre la feminidad, en su libro Espéculo de la otra mujer, es una lectura radicalmente crítica. En ese sentido, en una primera parte recuperaremos tres de las afirmaciones freudianas sobre la feminidad y su posterior relectura realizada por la autora francesa con el fin de indicar los modos en los que la crítica opera; y en particular, la crítica de género que tiende a mostrar, entre otras cosas, algunas conceptualizaciones ilegitimas sobre las mujeres. Finalmente, en una segunda parte, inspirados en las reflexiones de Butler y Foucault sobre la crítica, intentamos pormenorizar la crítica de la feminidad de Irigaray señalando que ésta no sólo tiene alcances puramente epistémicos, sino que además tiene alcances políticos y éticos. De ninguna manera pretendemos que ésta clase de ejercicio crítico se convierta en un modelo de dicha práctica, sino, por el contrario, nos interesa destacar el aspecto histórico, local y parcial de la misma. Nuestro objetivo es mucho más modesto: sólo nos interesa indicar que ésta forma de ejercicio de lectura crítica, lejos de generar daños a la teoría y a la práctica psicoanalítica en su conjunto, pueden contribuir al avance de los conocimientos en ambos sentidos; puesto que, digámoslo desde el comienzo, el saber no sólo se consolida cuando se documenta la

\footnotetext{
* Facultad de Psicología de la Universidad Nacional de La Plata, Argentina. Mail: casalerolando@yahoo.com.ar
} 
veracidad del mismo, sino que también lo hace cuando se deja claro que un conjunto de proposiciones que formaban parte de manera inauténtica de ese saber, son en cierta manera desmanteladas. La labor crítica, por supuesto, no está destinada a la destrucción del saber establecido; por el contrario, se orienta a la consolidación del mismo, siempre y cuando resista sus embates. Pero, en el caso de que parte de ese saber establecido no lograra superar el examen crítico, lejos de ser un perjuicio, ello es un gran beneficio, pues de esa manera se toma conciencia de que aquello que creíamos saber en realidad carecía de sustento y, por ello mismo, eran creencias que no hacian más que encubrir la ignorancia. La auténtica crítica, en última instancia, termina develando la ignorancia y el reconocimiento de la propia ignorancia es el punto ideal para iniciar una investigación; la crítica así entendida, no es creadora de saber, sólo nos conduce hacia la antesala de su producción.

\section{E1 ejercicio de la critica en torno a la Feminidad en el Psicoanálisis}

La critica ha sido entendida de modos muy diferentes que van desde el simple señalamiento de errores, equivocaciones y defectos, hasta la dilucidación de las capacidades de la razón para alcanzar el conocimiento. En este trabajo vamos a entender la crítica más bien como una tarea, como una actividad que conlleva una actitud. En éste sentido la crítica es inseparable de una disposición analítica según la cual se realiza una separación de juicios. La crítica se presenta de esta manera como una práctica de discernimiento. Ahora bien, esa práctica se ejerce sobre una base discursiva. De lo que se trata entonces es de identificar los diferentes elementos de un discurso, precisar sus sentidos y separarlos del resto, de forma que se los pueda concebir en su conjunto y en aquello que cada uno le aporta a la totalidad. La crítica es así, indisociable de una combinatoria. Ahora bien, resulta evidente que no todas las combinaciones son igualmente adecuadas: no 
todas las combinaciones tienen el mismo nivel de legitimidad. La crítica, en un sentido más preciso, está siempre ligada a una ponderación, a una valoración de los enunciados y sus diversas maneras de articularse entre sí. Esos enunciados llegan a ser expuestos a la crítica en la labor de lectura. De modo tal que no es descabellado imaginar una manera de leer que, lejos de apropiarse pasivamente del texto impreso, realice un acercamiento a ese texto de un modo radicalmente crítico. Ello, claro está, implica un posicionamiento incómodo de parte del lector ya que en esa tarea quedan suspendidas todas las certidumbres y puesto entre paréntesis el valor de verdad de las proposiciones. Leer criticamente implica un ejercicio a nivel lingüístico, pero cuando la crítica se radicaliza, queda expuesta a su propio límite: al marco referencial ofrecido convencionalmente por las diferentes reglas de composición de enunciados. De forma tal que la estructura gramatical con la cual se despliega el discurso crítico, así como las reglas referenciales y de eficacia productora de sentidos, queda implícitamente incluida en esa labor de cuestionamiento. En esos casos la crítica se vuelve reflexiva, aunque también abarque a las significaciones y referencias del discurso que está siendo examinado.

Cuando afirmamos que Irigaray hace una lectura critica de Freud y en particular de su conferencia sobre "La feminidad", estamos postulando que dicha autora va a tomar el texto freudiano como un material compuesto por una serie de enunciados sobre los cuales va a operar de modo analítico, separándolos unos de otros para precisar sus sentidos y las relaciones entre los mismos, a fin de ir delimitando la legitimidad con la que esos enunciados se entrelazan. La tarea de lectura de Irigaray está muy lejos de ser destructiva y aún mucho más lejos de ser una tarea puramente descalificatoria. Con su lectura no está destruyendo nada, ni tampoco está focalizada en señalar errores o defectos. No es esa su tarea primaria, sino desentrañar la trama con la cual Freud ha hilado su discurso sobre la Feminidad. Encontrar aquellos enunciados que sirven de nudos para ajustarse al resto, despejar las claves con las que unos enunciados llaman a otros y 
mostrar si esos llamados son o no pertinentes. Sería un grave error perder de vista ese espíritu crítico con el cual Irigaray hace su lectura de La Feminidad freudiana. Esa lectura, renglón a renglón, letra a letra, también se ocupa de los huecos, de los silencios, de aquellos puntos en donde el discurso se detiene, sitios que podrian ser puntos de partida de otras direcciones que, sin embargo, la autora no recorre. Criticar, en este sentido, no es simplemente establecer el nivel de legitimidad con que un enunciado se entrelaza con otro, ni tampoco es ir despejando las claves que rigen ese entrelazamiento. Leer criticamente es también, para Irigaray, captar las interrupciones de una narración que se detiene dónde podría avanzar, de una narración que avanza en ciertas direcciones cuando podría avanzar en otras. Es dejarse llevar por el insaciable deseo de saber sobre los hilos que manejan esa red de proposiciones hasta el punto de no claudicar ante posibles enredos ni mucho menos ceder ante lo que se da por sentado como obvio.

La densidad de la lectura de Espéculo de la otra mujer es inagotable y los caminos que abre son tan interminables como las aperturas sugeridas en la conferencia freudiana que le sirve de base y de la cual se la puede considerar como una extensión. Criticar un texto, puede ser entendido como llevar hasta el limite la extensión de sus significaciones.

De lo anterior se desprende que sería imposible en un simple artículo ofrecer las distintas implicancias contenidas en su critica, por lo que apenas estamos en condiciones de esbozar algunas de sus vetas. Sin embargo, consideramos valioso realizar esa tarea en la medida en que no sólo permite llevar el texto freudiano hacia sus fronteras recorriendo cada uno de sus laberintos, sino también porque en la lectura misma puede advertirse una dimensión de la crítica y una potencia de la crítica que muchas veces es subestimada. Es así que reconocemos en ese ejercicio de lectura no sólo una serie de operaciones sobre el texto, sino una práctica original que hace emerger los límites de un saber potenciando y convocando saberes adicionales. Una vez hechas estas aclaraciones, nos vamos a detener en algunos enunciados sobre la feminidad que nuestra autora nos invita a examinar. 
Básicamente y a modo de ilustración, elegiremos tres proposiciones de la conferencia freudiana sometidas a la lectura crítica y ejemplificaremos con más detalle lo que anteriormente hemos mencionado.

La primer proposición: Freud nos dice que el enigma de la feminidad no puede ser resuelto por la psicología y que "ese esclarecimiento, en efecto tiene que venir de otro lado y no se obtendrá hasta que no averigüemos cómo ha nacido, en general, la diferenciación del ser vivo en dos sexos" (Freud, 1991: 108). Freud llega a esta conclusión luego de haber rechazado acertadamente que la distinción entre masculinidad y feminidad no puede hacerse a partir de la identificación con la pasividad y la actividad (Freud, 1991:106) y de haber visto que, aún reformulada esa distinción en metas activas y metas pasivas, también resulta insuficiente (ibíd. p. 107). La lectura de Irigaray comienza por realizar una serie de señalamientos que irán a prefigurar el sentido y la dirección de su crítica.

Ella toma así la noción de diferenciación (Irigaray, 2007: 14) y comienza a explorarla tratando de despejar los motivos por los cuales la misma se podría volver una clave para entender la feminidad. No tarda en advertir que cuando se habla de los sexos, la irrupción de la diferencia pasa no sólo por distinguir uno de otro (sea en el plano diacrónico como sincrónico) sino en concebir la cuestión en términos binarios: el problema de la división de las categorías en dos, donde cada una de ellas será referida a la otra. Pero esa referencia de una categoría a la otra, esa manera de ver a la cuestión de los sexos en términos binarios y contrapuestos donde uno de ellos se termina convirtiendo en el que se identifica más con el origen que el otro, sin duda alguna presenta enormes dificultades. Es evidente desde el principio que para Irigaray todo proceso de diferenciación sexual, tal como lo concibe Freud, es tributario de una diferencia de los sexos concebidos en sólo dos categorias, donde, en última instancia, la problemática se termina reduciendo a la diferenciación de lo uno y lo otro. Para decirlo aún mejor, a la dialéctica de lo uno y lo otro, donde lo uno se convierte en el 
polo referencial y lo otro siempre termina en gran medida derivado; pues lo uno inevitablemente a lo largo del proceso de diferenciación siempre se termina convirtiendo como lo más originario, mientras que lo otros es calificado de modo necesario como menos originario. Esa distinción en más y en menos, por supuesto, lejos de apuntar a una distinción meramente cuantitativa de lo que es, terminaría siendo expresión de la asignación de una valor; y por supuesto, siempre lo otro, aparecería como menos valioso, o siendo menos originario. Es como si lo uno, más cerca de lo originario, diera los fundamentos para estipular el valor. Ahora bien, la lectura crítica de Irigaray, desde el principio nos alerta sobre las dificultades que se harán presentes en una concepción dialéctica del proceso de diferenciación entendido en ese sentido. No es una cuestión puramente ontológica, ni tampoco es una cuestión puramente valorativa, pasa por el modo en que el investigador se sitúa para concebir aquello que va a estudiar. Se trata de las categorías que se eligen como relevantes, se trata de los procesos que se deciden investigar, se trata del horizonte conceptual que sirve de base para concebir la diferencia. Es evidente para Irigaray que si se elige concebir el proceso de diferenciación sexual sobre las bases de una dialéctica parcial que reduce la masculinidad a lo uno y la feminidad a lo otro, aparecerán problemas que se derivan de esa misma dialéctica. No se trata de impugnar el estudio dialéctico de la diferenciación sexual, sino de mostrar los límites de un proceso de diferenciación sexual que termina reduciendo lo uno a la masculinidad y lo otro a la feminidad; se trata de mostrar las dificultades que emergen de elegir esa base conceptual para entender la diferenciación sexual, puesto que en esa elección misma ya se echan las cartas con las cuales se terminará jugando la partida. Es como si en ese juego de diferenciaciones las cartas estuvieran "marcadas" de entrada y se jugase con cartas conceptuales de esa clase. De lo que se sigue que uno de los sexos inevitablemente terminará quedando posicionado como menos originario y con un grado menor de ser y de valor que el otro. No es una cuestión estrictamente ontológica, no se trata de un traspaso a 
priori de las barreras que sitúan a la feminidad como un enigma; pues no es esa la posición en la que se coloca Irigaray al comentar críticamente a Freud. Simplemente señala que no hay, desde el principio, posibilidad alguna de tener grandes esperanzas; como sí las tenía Freud en que el conocimiento pleno del proceso de diferenciación de los sexos vaya a develar el misterio de la feminidad. Más bien podría ocurrir todo lo contrario, pues si el conocimiento de ese proceso de diferenciación sexual se termina llevando a cabo siguiendo los lineamientos de una dialéctica parcial, lejos de arrojar luz sobre la feminidad, terminaría cubriéndola con las peores formas de la ignorancia, donde se termina creyendo saber, sobre cuestiones sobre las cuales por las categorias empleadas para conocer, sólo se tiene desconocimiento bajo la falsa ilusión de un saber inauténtico. Esa dialéctica parcial se caracterizaría por el movimiento de la razón de lo mismo hacia lo otro reduciendo lo otro a lo mismo. Es decir, en el intento de atrapar lo otro, de apropiarse de lo otro bajo el formato ya preconcebido de lo uno que se presenta siempre como lo mismo (Femenías 2012: 94-95). Obviamente cuando lo mismo queda sustituido por el varón y lo otro por la mujer, ésta aparece como un reflejo, como una copia imperfecta de aquel. Evidentemente, esa imperfección o esa falta de cualidades no están en lo real, está introducido por el abordaje que se hace de lo real, por las categorías y la metodología que se emplea para aclarar ese supuesto enigma.

Lo anterior nos lleva a apreciar el lugar desde el cual Irigaray elabora su crítica a la segunda de las afirmaciones que vamos a examinar: "tenemos que admitir que la niña pequeña es como un pequeño varón" (Freud, 1991: 109). Mientras que Freud se encuentra forzado a aceptar esta afirmación por el modo en que se le imponen los hechos de la observación clínica, Irigaray parece estar buscando las razones por las que la observación clínica le muestra los hechos de esa manera. La autora claramente va desplegando una línea de argumentación en donde se va volviendo evidente que la observación le impone cierta violencia a lo real, porque esa misma observación ya está prefigurada 
con los conceptos de partida y con los modos de contrastar esos conceptos. En fin, si la diferenciación entre los sexos es la clave para comprender el enigma de la feminidad y si la diferencia buscada se realiza desde un marco general en donde lo uno y lo otro se presentan como protagonistas estelares de ese proceso, se impone como necesario un momento originario de indiferenciación, un momento fundante en donde lo uno y lo otro sean lo mismo, un momento donde el varoncito y la niña sean lo mismo. Es decir, un momento en donde la diferencia no haya comenzado a operar todavía. Irigaray no está diciendo que tal momento inicial no exista, ni tampoco está diciendo que la observación esté tergiversando los hechos, sino que está diciendo sutilmente que la observación estaba en cierta forma ya prestablecida por el punto de partida teórico elegido y que, como resultado, esa observación quedará inscripta dentro del marco discursivo con el que inicialmente se ha comenzado el análisis. En este sentido es que lo observado ejerce una violencia en lo real: desde el principio se ha adoptado un punto de vista masculino para resolver el enigma y ese punto de vista se lo ha identificado con el lugar del conocimiento científico y objetivo. Punto de inicio que la lectura crítica nos invita a revisar (Irigaray, 2007: 7). En su lectura se remarca que se trata de un hombrecito desfavorecido (Irigaray, 2007: 18), un hombrecito sellado con el signo de la inferioridad. La niña se ha convertido así en muy semejante al niño, pero inevitablemente destinada a dejar de serlo. La niña está llamada a ser lo otro del niño y es ahí donde se constata que su lugar ya estaba escrito en una clave que está muy lejos de beneficiarla y de darle un lugar central en la historia del desarrollo; la niña, está llamada a dejar de ser ese niño que fue; está condenada a devenir lo otro de ese niño. Pero no cualquier clase de otro, se tratará de otro devaluado desde el origen. Pues esa niña sólo puede ser un niño en virtud de la identificación del pene con el clítoris. Obviamente, aun siendo un niño, no lo es por completo, porque está signada en la comparación por la pesadumbre de un tamaño menor (Irigaray, 2007: 19). La empresa crítica nos invita a detenernos en estos nudos de discursos en donde 
convergen varios hilos y donde quedan estipuladas las posiciones centrales que se van combinando. Se trata de llamar la atención sobre el lugar desde donde se está produciendo el discurso, claramente masculino y se trata de mostrar que aquello que se presenta bajo el absoluto imperio de lo necesario, es en realidad, contingente, de que aquello que se presenta como hecho absoluto, es en realidad, relativo, de que aquello que se presenta como evidente, en realidad es confuso. Esa observación clínica que nos muestra a la niña como si fuera un niño pequeño, es una observación que requiere ser tamizada por la tarea crítica y cuando eso comienza a ocurrir resulta que su evidencia, su claridad, su carácter absoluto y su necesidad se vuelven dignas de ser puestas entre paréntesis. En fin, la crítica de género, en este punto nos coloca en el nivel de la suspensión de las creencias con respecto a la supuesta objetividad a la cual pretenden representar.

Todas las cartas quedan echadas cuando se nos plantean los dos grandes escollos que tendrá que superar ese pequeño varoncito que está llamado a devenir mujer: el cambio de objeto y de zona erógena (Freud, 1991: 110); que encontrará su punto culminante en el complejo de castración y la apertura y cierre del complejo de Edipo (ibíd. p. 119120). Ese recorrido por el cual la niña pequeña va deviniendo mujer normal (Irigaray, 2007: 21) no deja de ser un proceso donde una diferencia se va a agregando a otra y donde cada diferencia siempre es en relación a aquel niñito que ella fue. Se trata de diferencias que la van colocando en inferioridad. Por supuesto, la lectura crítica nos orienta a interrogarnos sobre ese proceso de selección de diferencias y sobre el silenciamiento de las otras diferencias, como aquella que muestra al varoncito desprovisto de matriz, diferencias que podrian haber colocado a esa niñita en otra situación (Irigaray, 2007: 16). El papel marginal de las diferencias positivas, no se debe a lo real, se debe más bien a un particular modo de emplear la razón según el cual el sujeto y su identidad se tornan centrarles y, en cambio, marginal la alteridad. En este punto hay concordancias con la importancia de develar el ocultamiento sistemático de las diferencias que terminan produciendo 
jerarquías en lo que es (Deleuze, 1988). Claro está, el proceso de diferenciación de la sexualidad infantil, el elemento privilegiado que marca todo ese proceso está constituido en clave masculina y está indicado por el papel hegemónico de un signo privilegiado cargado de connotaciones que conllevan jerarquías, a saber, el falo. Centro de la escena de la diferenciación y núcleo a partir del cual se instaura una división binaria de los sexos donde uno se presentará como más originario que el otro en virtud de su más perfecta adecuación a la economía fálica (Irigaray, 2007: 26). El varoncito, lo uno, se nos muestra así como el modelo cuya referencia al falo siempre es privilegiada, mientras que la otra del niño, siempre aparece atravesada por la carencia. Del lado del sujeto queda la plenitud fálica, del lado de la alteridad, queda la falta. Esa falta, es representada como menos valiosa que la plenitud y esa falta con la cual la alteridad queda desvalorizada resulta no ser otra cosa que una estrategia para dejar a lo otro merced a lo uno. Es decir, la alteridad, se va convirtiendo de esa forma en valor de uso o valor de cambio, un otro que está a disposición de uno. Sea del padre en la apertura del complejo de Edipo de la niña o sea en cualquiera de las manifestaciones de la maternidad que ulteriormente advendrá (Irigaray, 2007: 70-71). En fin, la lectura crítica de esta segunda proposición que nos muestra a la niña como un pequeño niño, no deja de exteriorizar las dificultades que se hacen patentes a la hora de enfocar el enigma de la feminidad con esquemas de una razón que tiende a colocar la alteridad en un segundo plano y a la mismidad en el primero. Pues esa clase de esquemas terminan trasladando al varón y a la mujer las escenas en donde lo primario es lo uno y lo secundario, la otra.

Estamos ahora en condiciones de centrar nuestra lupa en una tercera afirmación: "el hecho de que sea preciso a la mujer escaso sentido de la justicia tiene íntima relación con el predominio de la envidia en la vida animica" (Freud, 1991: 124).

Aquella reconstrucción que se ha realizado sobre el despliegue de la sexualidad y sus repercusiones, se nos muestra ahora con su total 
crudeza. Irigaray no deja de resaltar que de acuerdo a lo expuesto, la mujer termina siendo menos justa que el varón. Y eso es el resultado de que sea más envidiosa que el varón (Irigaray, 207: 104). Entre otras caracterizaciones tales como su narcisismo más elevado, su incapacidad para sublimar, sus intereses sociales más endebles, por citar sólo algunas. Al intentar resolver el enigma de la feminidad, Freud ha tropezado, sobre el final, con una mujer que es menos que el varón, desde varios respectos. El arduo recorrido por las diferentes fases del desarrollo sexual que ha llevado desde la niña a la mujer, termina mostrándonos que al final de cuentas la mujer es menos que el varón. Irigaray no se sorprende de semejante resultado, porque en su lectura crítica fue marcando todos aquellos nudos del discurso que venían prenunciando ese desenlace final; sin embargo, no deja de ser impactada por la fuerza de las afirmaciones con las que se desprecia a la mujer. Y cuando pone bajo su lupa el "escaso sentido de la justicia", no puede dejar de evocar una antigua pieza literaria de Sófocles, en la que el rey Creonte acusaba a Antígona de su carente sentido de justicia (Sófocles, 1997). Aquello nuevo que el psicoanálisis viene a decir sobre el enigma de la feminidad pierde toda su originalidad por haber sido expresado miles de años antes. Sin embargo, lo novedoso aquí parece pasar por la justificación y por el particular modo en que se habla de la femineidad, para terminar justificando afirmaciones tales como la de que las mujeres son más injustas que los varones. Evidentemente, en los tiempos de Sófocles, un Creonte, no necesitaba justificar su creencia; miles de años después, esa creencia comenzaba a ponerse en duda y había que darle alguna clase de fundamento. Está muy claro que había opciones: se podría haber enfatizado en todos aquellos hechos de observación clínica que hacían insostenible creer en que todas las mujeres son más injustas que los varones; sin embargo, se elige otro camino, que en cierta manera duplica la apuesta; y al elegirlo, resulta que esa incapacidad de las mujeres para ser justas, se debe a su sexualidad infantil, se debe a que no han sido capaces de procesar su envidia. En definitiva, el "hecho" de que las mujeres sean más injustas 
tiene causas y se remontan a la situación infantil donde fueron víctimas de la envidia de pene. Es una pena tanta pobreza argumentativa. Realmente nos deja perplejos semejante manera pueril de razonar cuando en otros aspectos el autor de esos razonamientos ha sido brillante. En fin, cuando la crítica se hace radical, uno de sus efectos es el de la perplejidad, mientras que para muchos lectores acríticos de Freud el despliegue de la sexualidad femenina y su consecuente destino final, les han parecido perfectamente normales. Para una lectura crítica radical, por el contrario, es una fuente de completa perplejidad. Y por supuesto, una invitación para abrir nuevos caminos de indagación. La crítica por sí sola no es capaz de generar conocimientos, pero al mostrar los límites del saber vigente, revela la imperiosa necesidad de lanzarse hacia nuevos saberes que se presentan así como posibles. Realizar una lectura crítica, no es una tarea demoledora, no se trata de demoler el edificio construido laboriosamente por el saber, se trata de mostrar más bien que ese edificio carece de bases o tiene bases que no son las apropiadas.

En un bello giro dialéctico de ejercicio de la lectura crítica, Irigaray muestra lo extraño de la exigencia de sentido de la justicia a la mujer, cuando en aquellos tiempos las mujeres estaban siendo víctimas, aún más que ahora, de terribles injusticias que tenian a los varones como victimarios. Curiosa manera de tomar nota de la situación social en la que estaban atrapadas las mujeres de aquellos tiempos. De acuerdo a lo que se nos dice en la conferencia, eran ellas quienes no tenían sentido de la justicia; los varones, los victimarios, esos sí tenían sentido de la justicia. Es realmente asombroso que el creador del psicoanálisis no se haya percatado de la opresión que sufrían las mujeres de su tiempo, es realmente asombroso que no se haya dado cuenta del lugar que ocupaban en el espacio social y la denegación de derechos de la que eran víctimas. $\mathrm{Y}$, por supuesto, a nuestros ojos se presenta como ofensivo que las acusara a ellas de ser injustas, cuando ellas eran quienes estaban sufriendo terribles injusticias en manos de los varones. Pero lo más terrible, quizás no sea eso, sino que ese particular 
posicionamiento de las mujeres con respecto a la justicia sea atribuido a una supuesta envidia no resuelta, vinculada a episodios infantiles. Desvinculándolo de la situación concreta que las mujeres atravesaban en aquel entonces.

En fin, si tomamos el análisis de las tres proposiciones estudiadas en su conjunto y nos focalizamos en la lectura emprendida por Irigaray, es posible vislumbrar una inversión en donde lo primero adquiere significado a partir de lo último (Femenías, 2012: 158-159). Con lo cual, la tarea crítica no es otra cosa que una develación, un hacer presente aquello que estaba oculto y que nos coloca ante la cuestión del origen y la necesidad del régimen patriarcal de apropiación del cuerpo y la fecundidad de la mujer, generando así el ocultamiento de los pilares que sustentan su opresión. El acto de conocer, en este sentido, resulta inseparable del poner de relieve lo auténticamente originario; pero ese acto es imposible a menos que se lleve a cabo la inversión de los postulados que han colocado al falo como el eje central sobre el que gira el logos (Femenías, 2012: 99-100).

\section{Hacia una concepción de la crítica como ejercicio de la virtud:}

Como se mencionó anteriormente, es posible atribuirle muchos sentidos a la crítica, sin embargo, a nosotros nos interesa avanzar en la crítica entendida como una actitud orientada a la determinación de la legitimidad de los enunciados. No sólo mostrar el modo en que esa actitud se puede ejemplificar como el caso concreto del trabajo de Irigaray sobre la feminidad, sino también, avanzar en una caracterización detallada de esa actitud.

A nuestro entender es Foucault quien nos ofrece un sólido punto de apoyo. Para él, esa actitud implica una disposición que tiene un momento histórico en su aparición y que a su vez presenta una estrecha vinculación con el gobierno, como una instancia de negación a ser gobernado (Foucault, 2006: 8). Negación que no hace referencia al gobierno en general, pues no se trata de una actitud que se opone por 
medio de la negación a cualquier práctica de gobierno, sino que se trata de la negación concerniente a ciertos principios, formas, objetivos, procedimientos o agentes (Foucault, 2006: 7-8). En definitiva, la crítica, entendida como una actitud, se vincula a las distintas virtualidades que están implícitas en todo gobierno. La negación que instaura la crítica muestra que no todas esas virtualidades son aceptables. Por eso no es de sorprender que en el surgimiento histórico de esa actitud crítica encontremos referencias religiosas y una contraposición a las maneras de gobierno que se pretendian sostener apelando a los textos sagrados; ya que en esos mismos textos era posible vislumbrar otras maneras de gobierno (Foucault, 2006: 9). Al mismo tiempo, aparece también la invocación a principios que prevalecen por sobre las leyes vigentes; es decir, es el momento de la aparición de una clara conciencia de que las leyes no respaldadas en principios universalmente válidos para todos pueden ser radicalmente injustas (Foucault, 2006: 9-10). Además, la negación a ser gobernado de un modo particular, por supuesto pone en juego a lo verdadero, dejando claro que la verdad no se puede establecer por quienes tienen más autoridad (Foucault, 2006: 10).

En otras palabras, Foucault nos indica que la actitud crítica, tal como ha surgido históricamente, no puede reducirse en modo alguno a una forma de operar de la razón para determinar la validez o legitimidad de los enunciados en función de su correspondencia con la realidad o en función de la presencia de contradicciones. La crítica, por supuesto, no se desentiende de esas cuestiones, pero bajo ninguna manera puede ser limitada sólo a ellas, la crítica pensada como actitud es indisociable en su surgimiento del reconocimiento de los límites al gobierno, al descubrimiento de que no cualquier manera de gobernar es legítima. En fin, la crítica encuentra su espacio propicio para germinar, en las extralimitaciones del ejercicio del poder.

Es conveniente precisar aún más el sentido de los términos y para ello nos detendremos brevemente en la definición de actitud, entendiéndola como "un modo de relación con respecto a la actualidad; una elección voluntaria que hacen algunos; en fin, una manera de 
pensar y de sentir, una manera también de actuar y de conducirse que, simultáneamente, marca una pertenencia y se presenta como una tarea" Foucault, 2006: 82). Es claro, la noción de actitud, implica una cierta relación con los enunciados y la verdad que estos puedan contener, pero por sobre todo es una relación con la actualidad, un modo particular de sentir, pensar y actuar. Pero, lo más relevante es que la actitud pasa por una disposición voluntaria, esto es por el ejercicio de la libertad, con la capacidad para elegir; y es en este punto que toda actitud, además de ser una cuestión epistémica, es al mismo tiempo un asunto radicalmente ético.

Por otro lado, si continuamos precisando los términos, vamos a ver que "la crítica dirá, en suma, que nuestra libertad se juega menos en lo que emprendemos, con más o menos coraje, que en la idea que nos hacemos de nuestro conocimiento y de sus límites" (Foucault, 2006: 13). Al conjugarse ambas nociones, la de critica y la de actitud, nos queda entonces una disposición radicalmente ética que pone en juego al pensar, al sentir y al actuar en el ámbito de las elecciones. Además, nos queda el surgimiento de un tipo particular de saber, capaz de reconocer los límites en los cuales él mismo es capaz de constituirse como tal. Se trata de un saber de segundo orden, no de un saber que tiene como contenido un tema particular, sino de un saber que se vuelve sobre sí mismo para establecer aquello que es capaz de captar como genuino conocimiento. Ese carácter reflexivo de la crítica está muy lejos de reducirse a una mera expansión y ampliación de la razón hacia espacios cada vez más alejados de la vida. El proyecto crítico, en este sentido, no deja de estar enraizado en las relaciones de poder desplegadas en la vida social, en donde los marcos que hacen posible y legitima la obediencia al soberano no dejan de ocupar un papel importante en ese escenario en el que la critica se desarrolla (Foucault, 2006: 14).

Es importante señalar que la labor crítica se presentará entonces inscripta en las condiciones históricas en las que se encuentra aquel saber al que ella se aplica y también se dirigirá hacia la red de 
relaciones en la que se encuentra ubicado aquello a lo cual el saber hace referencia. De esta forma, la crítica presentará un aspecto arqueológico y un aspecto genealógico (Foucault, 2006: 91-92).

La crítica se vuelve así una empresa situada históricamente, una práctica que devela las relaciones de aquello que es y, en particular, de aquello que es por excelencia, a saber, el ser humano. De esa forma, la crítica se orienta hacia los límites y las coerciones en los que se hace posible la existencia de ese ser enigmático que somos; se trata de una crítica que se vuelve ontológica porque se perfila hacia el hombre, hacia la antropología: se interesa por éste en tanto ser, de ahí que a pesar del pasaje inevitablemente antropológico, la crítica se torna ontológica; puesto que intenta despejar los límites en los que se recorta el ser cuya existencia, por su propia especificidad histórica, tiene cierta primacía por sobre todo lo que es (Foucault, 2006: 93).

En ese sentido, la crítica orientada hacia el ser humano en aquello que éste tiene de histórico, es una crítica que intenta develar los límites de la existencia y las posibilidades de superarlos. Dos serán así las características principales de la misma: por un lado, será parcial, se opondrá a todo proyecto universalista y, por otro lado, será local, es decir, se referirá a dominios, a áreas muy precisas del quehacer humano.

De esta forma, la crítica no puede ser caracterizada principalmente como una doctrina, teoría o cuerpo de saber, sino que más bien conviene entenderla como una práctica, como un ejercicio constante de análisis histórico de los límites que nos son impuestos para llegar a ser, así como la posibilidad real de transgredirlos (Foucault, 2006: 97).

Sería conveniente, retomar la práctica de lectura de Irigaray llevada adelante para realizar el análisis del discurso sobre la feminidad. Allí se vislumbra que aquello que está en juego es el estudio de los límites de nuestro ser y las posibilidades de traspasar dichos límites. Límites que se corresponden con una cuestión muy especial que permite hacer comprensible el modo en que nos hemos organizado: se trata de la división sexual, se trata de que nuestras sociedades se encuentran 
atravesadas de un modo o de otro por la división de los seres humanos en dos sexos; cosa que se ha presentado habitualmente como un dato, como un hecho absolutamente obvio que no merecía ninguna clase de reflexión y que era el punto de partida de cualquier análisis, cuando en realidad no es para nada obvio que nuestras sociedades aparezcan marcadas por la división de los seres en dos sexos. Irigaray avanza en la dirección de colocarnos en la situación de asombro, de hacer que esa división, lejos de ser una certeza inamovible, sea un asunto que nos llene de asombro y que permita suscitar el deseo de saber. Para ello, la lectura crítica viene en su auxilio, pero no tanto como una herramienta o como un medio para alcanzar un fin, sino más bien como una práctica de indagación que se interroga y que interpela sobre aquello que está dicho, sobre aquello que se presenta como lo inamovible y lo incuestionable. En ese sentido, es un ejercicio llevado adelante en la frontera misma del saber y la ignorancia, en esa zona difícil de habitar en la cual muchos creen saber lo que no conocen y otros tantos creen que es imposible acceder a los nuevos territorios desconocidos porque son insuficientes los recursos y categorias disponibles para hacerlo. En esa región fronteriza, en esa región de incertidumbres es donde queda situada Irigaray; a tal punto que la división de los sexos ya no puede ser reducida a un mero dato, sino que más bien habría que concebirla en relación a una particular forma de gobierno, a una actitud y a un modo especial de conocer. La crítica de Irigaray a los textos freudianos sobre la feminidad se encuentra posicionada en esos tres niveles, de modo tal que por un lado apunta hacia aquellas condiciones que fijan a los seres humanos atravesados por la división de los sexos y, por otro lado, al pretender descifrar las claves de esa diferenciación propone avanzar hacia los modos de transgredirla, hacia formas posibles de superarla y transformarla. Se trata de una lectura que reúne muchas de las condiciones que se encuentran en el ejercicio de la crítica y de un modo particular de crítica a la que Butler pensará como una puesta en acción de la virtud (Butler, 2004). 
Para avanzar aún más sobre sobre la tarea realizada por Irigaray en Espéculo de la otra mujer, resulta conveniente profundizar aún más en torno al concepto de critica y valernos de algunas conclusiones a las que ya hemos arribado cuando efectuamos un estudio sobre la concepción de la crítica en Butler (Casale, 2014).

De acuerdo a nuestro entender, siguiendo el camino trazado por Foucault, Butler nos sugiere la posibilidad de reconocer al menos tres campos vitales de la crítica: el político, el epistemológico y el ético. Por supuesto, esos campos son inseparables en la práctica, pues en el acto de criticar siempre operan juntos y se revelan en la actitud, tal como la hemos definido en términos de Foucault; pero esos campos pueden ser distinguidos y es en este sentido que la crítica tendría, analíticamente hablando, al menos esos aspectos. Nos interesa mostrar que tales aspectos están presentes en la lectura de Irigaray sobre la feminidad y para ello retomaremos algunas de las cuestiones que ya hemos considerado anteriormente, pero ahora teniendo en cuenta los ejes sugeridos por Butler, que nos permiten recorrer de manera específica el trabajo realizado por la autora de Espéculo de la otra mujer.

Examinemos los alcances políticos de la crítica de Irigaray, los cuales, tal como ha mostrado Butler, conciben la crítica como destinada a precisar los limites del gobierno, es decir, a señalar las condiciones en las que gobernar es aceptable (Butler, 2004). Más precisamente, la crítica entendida como una negación de los excesos del poder de los gobernantes, para expresarlo de otra manera (Foucault, 2006). E1 mérito de Irigaray al leer la conferencia sobre la feminidad radica en que ella da cuenta de que gran parte de los enunciados expresados allí por Freud en realidad se están refiriendo al modo en que los varones pretenden gobernar a las mujeres y su trabajo consiste en mostrar a sus lectores que afirmaciones tales como "las mujeres tienen menor sentido de la justicia que los varones" están muy lejos de justificarse por otras afirmaciones o por su correspondencia con supuestos hechos clínicos o de cualquier otra clase. Ella nos revela que ese tipo de afirmaciones en realidad no son otra cosa que los fundamentos de un 
modo de gobierno, para decirlo en términos de Foucault. De eso se trata justamente el drama trágico en el que quedan envueltos Antígona y Creonte, citado por Irigaray. Se trata de una mujer que realiza una negación de los principios y leyes sobre los cuales un tirano pretende asentar sus actos de gobierno. Por supuesto, se puede creer que las mujeres como Antígona carecen de sentido de la justicia y que no son capaces de incorporar el sentido de la ley; pero lo que no se puede hacer es ignorar que quienes sostienen esa postura están defendiendo un modo de ejercicio del poder completamente abusivo y opresivo que cercena los derechos de las mujeres. En definitiva, es posible hacer como hace Freud en su conferencia y argumentar sobre la incapacidad de las mujeres para ajustarse a la ley y la justicia, pero no es posible quitarle a Freud la responsabilidad del peso de lo que está diciendo y de lo que está haciendo al decirlo. Para la lectura crítica de Irigaray, no está haciendo otra cosa que justificar un modo injusto y opresivo del gobierno de las mujeres en donde éstas quedan reducidas a meras mercancías. Las afirmaciones freudianas sobre la supuesta incapacidad de las mujeres para comprender lo que es justo, encubre y oculta la colosal ignorancia de los varones que han terminado colocando a las mujeres, en su desenfrenado intento de gobernarlas, en una situación de tremenda injusticia. Por supuesto, en nuestros dias un psicoanálisis que padezca de semejante ceguera es absolutamente inaceptable porque sería un psicoanálisis que se volvería cómplice de los victimarios.

Pasemos a considerar, ahora los alcances éticos de la crítica, que nos invitan a entenderla como una práctica ética, pues el tener el coraje de valerse de la propia razón, es en última instancia asumir el riesgo de la sanción de las autoridades que pretenden una obediencia incondicional (Butler, 2004). La virtud se pone de relieve en los actos de negación que se contraponen a los abusos de poder y a todos aquellos enunciados que pretenden sustentarlos y apoyarlos. Irigaray no deja de insistir en este punto y no deja de señalar que muchas de las proposiciones sostenidas en las conferencias están cargadas de imperativos morales que son encabezados bajo la forma lingüística "la niña debe..." (Freud 
1991), generalmente referidos a los pasajes que la van alejando de su semejanza inicial con aquel pequeño niño que fue. De esa forma, muchos de los enunciados que supuestamente describen el proceso de convertirse en mujer "normal" van acompañados por el verbo deber y sus correspondientes connotaciones moralizantes (Irigaray 2007: 23). Despejar el carácter moralizador de una gran cantidad de los enunciados expuestos en las conferencias freudianas permite identificar aquellas marcas del texto que escapan a la supuesta descripción que pretende realizar y con ello revelan que gran parte del contenido de lo ahí expresado no se refiere sino a una serie de prescripciones, a una serie de imperativos para que la niña devenga mujer "normal". Ahora estamos en condiciones de comprender más claramente su significación: esa "mujer normal" no es otra, en última instancia, que aquella que va a resultar gobernada. En una sociedad organizada patriarcalmente no es de sorprender que las normas terminen situando a las mujeres en esa condición. Pero, sí es de sorprender que un saber que ha permitido y ha contribuido en gran medida a un gran número de mujeres que padecian sintomas, quede atrapado en esa trampa de la moralidad bajo la forma de la descripción de supuestos hechos. Evidentemente, los alcances éticos de la crítica, no se refieren simplemente a destacar un conjunto de enunciados que, lejos de expresar una descripción de lo que sucede, no son más que prescripciones patriarcales por medio de las cuales los varones se aseguran el control y gobierno de las mujeres.

La crítica supone valerse de la propia razón y ello implica que hay quienes no han tenido ese valor y han quedado sojuzgados bajo el imperio de la autoridad patriarcal y quienes, como Irigaray, tienen el coraje de decirlo todo aún a riesgo de su propio ser y de la expulsión de la comunidad a la que pertenecía. Es en ese sentido que la crítica se vuelve una práctica de la virtud.

Finalmente, tenemos los alcances epistémicos de la crítica, que están orientados a develar las condiciones que hacen posible el surgimiento de aquellos enunciados que van a formar parte del saber hegemónico. 
Se vuelve necesaria si consideramos que los regimenes hegemónicos de saber tienden a borrar y cancelar el modo en que los enunciados emergen como válidos (Butler 2004: 307).

En la lectura de la conferencia freudiana llevada a cabo por Irigaray, también encontramos este componente, especialmente cuando se esfuerza por mostrar que muchas de las afirmaciones de Freud están inspiradas en su ideal: alcanzar la resolución del enigma de la feminidad a partir del descubrimiento de las claves del proceso de división de los sexos. Sin embargo, el horizonte epistémico en el cual ese proceso se funda no es otro que el de una dialéctica parcial que termina reduciendo lo otro a lo uno que desempeña el papel de sujeto y que de alguna manera termina cancelando las diferencias positivas para sobrevalorar las diferencias negativas.

En definitiva, es un tema de discusión y debate el grado en que estos niveles de la crítica están presentes en la lectura de Irigaray, pero a nosotros nos basta con mostrar que la crítica de género conlleva estos niveles y en cierta manera los promueve. Se trata de una crítica en acción, de una tarea interminable, de una tarea siempre parcial y localizada, de una tarea que expresamente se despliega en torno de lo que somos, de las condiciones que fijan sus límites y de la posibilidad de traspasarlos; se trata de una empresa que necesariamente se lleva adelante dentro de un marco histórico y que apunta a ampliar nuestras libertades en la medida en que despeja la existencia de muchos condicionantes que se presentan como necesarios pero que, en realidad, resultan ser contingentes y sujetos a modificación. La crítica no es productora de saber, pero en última instancia es un llamado al saber que amplie nuestras libertades.

\section{Conclusión}

El ejercicio de la práctica crítica realizado por Irigaray no tiene como finalidad impugnar la teoria de Freud sobre la feminidad y sobre la sexualidad de la mujer; más bien pretende depurarla de una serie de 
afirmaciones que carecen de justificación suficiente. Nosotros nos hemos ocupado de tres de ellas y con el fin de ejemplificar el modo en que la crítica se ejerce. Se trata de una crítica focalizada, situada e inscripta en un contexto histórico y por ello mismo parcial, pero sin embargo, no deja de ser efectiva pues aquellos enunciados sometidos a la crítica que no logran superar el examen de la misma, ya no pueden sostenerse de modo racional y se abre así la empresa de reformularlos o de generar otros nuevos que vengan a sustituirlos. La crítica enmarcada en la teoría de género y aplicada sobre la feminidad ha logrado su objetivo: mostrar los límites de un conjunto de proposiciones que se ofrecian como saber. La critica nos ha conducido hacia las puertas de nuevos conocimientos y será tarea de los investigadores producirlos; nos ha colocado ante la situación de ignorancia una vez que ha hecho evidente que algunas de las proposiciones en torno de la feminidad no se encuentran sólidamente justificadas y, por el contrario, son generadas por un modo abusivo de ejercicio del poder sobre las mujeres de parte de los varones. No se trata de negar la sexualidad infantil y mucho menos la sexualidad de la niña o el niño, se trata más puntualmente de dejar en claro que muchas de esas afirmaciones no tienen otra finalidad que la de intentar dar falsas excusas para asegurarles a los varones las condiciones de gobernabilidad de las mujeres, de modo tal que, por lo menos en las tres proposiciones estudiadas en nuestro trabajo, resulte evidente que las mismas no se fundan en lo real y mucho menos en otras proposiciones, sino que se fundan en un modo abusivo de gobierno. La crítica de Irigaray a los textos freudianos sobre la feminidad descansa en una radical negación, de no ser gobernada en nombre de ese saber y no ser gobernada a costa del desconocimiento de los derechos fundamentales de las mujeres; de no ser gobernada por aquellos varones que se erigen a sí mismos como sujetos y reducen a la mujer a una subalterna sometida. En definitiva, no ser gobernada a costa de quedar reducida a una mercancía que circula entre tantas otros bienes que solo los varones pueden usar o intercambiar. En definitiva, la crítica de Irigaray es al mismo tiempo 
una puesta en evidencia de los límites de ciertas proposiciones como una invitación y una convocatoria a producir un saber que tenga un hondo contendido ético y político además de epistémico.

\section{Referencias bibliográficas}

Butler, J (2004). "What is Critique? An Essay on Foucault's virtue". En: S. Salih and J. Butler (eds.), The Judith Butler Reader. Oxford: Blackwell.

Butler, J (2006). Deshacer el género. Barcelona: Paidos.

Butler, J. (2009). Dar cuenta de sí mismo: Violencia ética y responsabilidad. Buenos Aires: Amorrortu.

Casale, R. (2014). Algunas notas en torno a la crítica: Sugerencias de Butler y Foucault. Sapere Aude, 5(9), 167-183.

Castro, E. (2004). El vocabulario de Foucault. Bernal: Universidad Nacional de Quilmes.

Deleuze, G. (1988). Diferencia y repetición. Gijón: Júcar Universidad.

Descombes, V. (1988). Lo mismo y lo otro. Madrid: Ediciones Cátedra.

Fedullo, L. (2002). La vinculación de lo femenino con la muerte, en la representación masculina. GénEros, 10(28), 59-63.

Femenías, M.L. (2003). Judith Butler: Introducción a su lectura. Buenos Aires: Catálogo

Femenías M. L. y Soza Rossi, P. (2011). Saberes situados / Teorias trashumantes. La Plata: Editorial UNLP.

Femenías, M. L. (2012). Sujeto y Género. Buenos Aires: Prohistoria Ediciones.

Femenías, M. L, y Martínez A. (2015). Judith Butler. Las identidades del sujeto opaco. La Plata: FaHCE.

Foucault, M. (1992). El orden del discurso. Buenos Aires: Tusquets, Foucault, M. (2003). Historia de la sexualidad. 2, El uso de los placeres. Buenos Aires: Siglo XXI. 
Foucault, M. (2006). Sobre la Ilustración. Madrid: Tecnos.

Foucault, M. (2010). El coraje de la verdad. El gobierno de si y de los otros II. México: Fondo de Cultura Económica.

Irigaray, L. (2007). Espéculo de la otra mujer. Madrid: Aikal.

Kant, I. (2009). Crítica de la razón pura. Buenos Aires: Colihue,

Kant, I. (2004). ¿Qué es la Ilustración? Y otros escritos de ética y filosofía de la historia. Madrid: Alianza.

Salih, S. (2002). Judith Butler. London: Routledge.

Sófocles (1997). Antigona. Buenos Aires: Eudeba. 